\title{
Cerebral Palsy In Adults Consequences of Non Progressive Pathology
}

\author{
Mohammed Abdulelah Mezaal*, Kasid A. Nouri, Shareefa Abdool, Khalid Al Safar and Ahmed \\ S.M. Nadeem
}

Neurology Department-Rashid Hospital, P.O. Box 4545, Dubai-UAE

\begin{abstract}
Objective: Cerebral palsy (CP) is a disability that affects individuals throughout their lifespan. This study was conducted to evaluate the clinical status of adults with cerebral palsy.

Methods: A cross-sectional study was carried out during the period of February 2001 to June 2002, in Baghdad, Iraq. Fifty young adult men with cerebral palsy were evaluated by reviewing their medical records and present clinical status.

Results: Antenatal maternal medical problems were recorded in 17 (34\%) cases. Kernicterus was the most common possible cause occurring in 14 (28\%) cases. Spastic hemiplegia was reported in 16 (32\%) patients. Various forms of combinations occured in $14(28 \%)$ cases. Of the secondary disabilities, musculoskeletal disorders were the most common (60\%), followed by epilepsy (42\%), mental retardation (40\%), speech disorders (30\%), bladder dysfunction (4\%) and visual impairment $(2 \%)$. Relationships between musculoskeletal deformities and the development of mental retardation were statistically significant (P value 0.0001).
\end{abstract}

Conclusion: Adults with $\mathrm{CP}$ are at risk of many highly preventable secondary conditions that cause loss of function and deterioration of quality of life.

Keywords: Cerebral palsy, musculoskeletal disorders, neurology, static encephalopathy.

\section{INTRODUCTION}

Cerebral palsy $(\mathrm{CP})$ is a non-progressive disorder of motor function [1]. It describes a diverse group of disorders of movement, posture, and tone due to a central nervous system insult [2]. Though most cases have their origin in the antepartum period, newborn encephalopathy represents a crucial link between intrapartum events and permanent neurological problem in the child [3]. Intraventricular hemorrhage \& hyperbilirubinemia have strong correlations with the subsequent development of CP [4-6]. Cerebral palsy is classified according to extremities involved (monoplegia, diplegia, hemiplegia, triplegia and quadriplegia) and the characteristics of the neurologic dysfunction (spastic, dyskinetic, ataxic, hypotonic or a combination) [7]. The clinical type of cerebral palsy is considerably less informative for prognostic purposes than categories of functional disability [8]. Periventricular leukomalacia \& middle cerebral artery infarctions were the most common etiological factors documented by radiological \& pathological studies $[9,10]$. Although $\mathrm{CP}$ has been predominantly considered as a childhood pathological condition, the evolutions of the effects of CP do not stop at 16-18 years of age [11-14]. In contrast to the care provided for children with disabilities, organized health care for adult patients has been described as very poor, with notable reduction of provision once the patient reaches adulthood [11, 15, 16]. Over the past 10 years, there has been great interest in describing the health and functional status of adults with $\mathrm{CP}$,

*Address correspondence to this author at the Neurology DepartmentRashid Hospital, P.O. Box 4545, Dubai-UAE;

E-mail: moh66_6@hotmail.com but the problem that research faces in this field is difficulty in accessing the patients.

\section{METHODS}

\section{Clinical Study Design \& Participants}

A cross-sectional study was carried out in one teaching center for neurological diseases. A total of 50 young adults with CP were included. The study was carried out during the period of February 2001 to June 2002, in Baghdad, Iraq. All patients (men) were referred to a neurological center in Baghdad from different provinces for the evaluation of recruitment fitness. Because most patients with $\mathrm{CP}$ after adulthood did not seek help from medical services regarding their neurological status, recruitment centers are good place for reviewing these patients.

\section{Clinical Monitoring}

Data was comprehensively collected by interviewing the parents of the patients (mothers or mothers \& fathers) and by reviewing the pateints' medical records. All patients who were presented alone ( 7 patients) or without prior medical reports ( 3 patients) were excluded from the study due to lack of sufficient history. History of medical problems during pregnancy, perinatal complications, type of delivery and neonatal illnesses was taken from all patients. Information was taken on age at diagnosis and clinical features of the disease, including the type of CP and associated abnormalities. School performance, mini mental state assessment (MMSA) and reports from prior health care providers were used in evaluation of mental status. Power was evaluated according to scale from Zero (no movement) to 5 (full range of power). 


\section{Statistics}

Was done according to Fisher's Exact Test. P value $<0.05$ was considered significant.

\section{RESULTS}

Fifty patients were enrolled, with mean age at presentation 20.5 years, ranging from 18-23 years. All patients (men) were examined for recruitment fitness. Positive maternal medical history was reported in 17 patients (34\%). Smoking, medications history, hypertension and eclampsia were the most common maternal problems during pregnancy. Fortyone patients $(82 \%)$ were delivered by normal vaginal delivery, $5(10 \%)$ by forceps delivery, and 4 patients $(8 \%)$ were delivered by Caesarean section. Preterm delivery occurred in 8 patients (Gestational age range from30-33 weeks). Regarding the possible causes of $\mathrm{CP}$, we found that kernicterus was the most common cause (28\%) followed by asphyxia and (hypoxic-ischemic encephalopathy) (16\%), and meningoencephalitis during the first year of life $(16 \%)$. No causes were found in $32 \%$ of the patients.

Spastic hemiplegia was the most common type of CP seen in 16 patients (32\%). Different forms of combination occured in 14 patients (28\%) (Table 1). Of the secondary disabilities that accompany $\mathrm{CP}$, musculoskeletal disorders were the most common, occuring in 30 patients $(60 \%)$ (Table 2). Speech problems ranging from mild dysarthria to global dysphasia presented in all cases show a direct effect rather than a sequel of $\mathrm{CP}$. All patients who were born prematurely developed neonatal complications. Relationships between musculoskeletal deformities and the mental retardation (IQ impairment) were statistically highly significant (P value 0.0001) (Table 3).

Table 1. Pattern of Cerebral Palsy in Adults

\begin{tabular}{|c|c|c|}
\hline Pattern & No. & \% \\
\hline \hline Spastic & & \\
Hemiplegia & 16 & 32 \\
Quadriplegia & 9 & 18 \\
Diplegia & 6 & 12 \\
Dyskinetic & 2 & 4 \\
Dystonia & 1 & 2 \\
Chorioathetosis & 1 & 2 \\
Ataxic & 1 & 2 \\
Atonic & 5 & 10 \\
Combined & 5 & 10 \\
Spastic diplegia and ataxia & 4 & 8 \\
Spastic quadriplegia and dyskinesia & & \\
Spastic hemiplegia and dyskinesia & & 100 \\
\hline Total & 50 & \\
\hline
\end{tabular}

Table 2. Complications of Cerebral Palsy

\begin{tabular}{|c|c|c|}
\hline Type & No. & \% \\
\hline \hline Musculoskeletal disorder & 30 & 60 \\
Epilepsy & 21 & 42 \\
Mental retardation & 20 & 40 \\
Speech difficulties & 15 & 30 \\
Bladder dysfunction & 2 & 4 \\
Visual impairment & 1 & 2 \\
\hline
\end{tabular}

\section{DISCUSSION}

$\mathrm{CP}$ is well studied in the west, but less is known about its prevalence in the developing world. I have, in this paper, attempted to quantify the range of disabilities that might be expected to occur in such population. Age of patients ranged from 18-23 years and all of them were male, because the study was conducted on the patients referred for recruitment fitness. Maternal medical events were reported in 17 patients (34\%), which may cause brain damage or increase the infant's vulnerability to future events. This observation is in agreement with Davis's belief about the etiology of cerebral palsy, and Suzuki et al. theory that prenatal etiological factors account for about $35 \%$ of CP cases [1, 17]. Most patients in this study were delivered by normal vaginal delivery (82\%), which is in agreement with Freud's suggestion that cerebral palsy, might represent "symptoms of deeper-lying influences which have dominated the development of the fetus". Difficult labor had a minor role in the pathogenesis of $\mathrm{CP}$ and difficult labor itself in certain cases was merely a symptom of deeper effects that influence the development of fetus. Kernicterus was the most common identified cause (28\%), which can be explained as a relatively high prevalence of RH incompatibility of parents in our country and the region. No known perinatal or neonatal causes were reported in $32 \%$ of cases, which is in agreement with previous reports $(17-60 \%, 35 \%)[1,17]$. Spastic hemiplegia was the most common form of $\mathrm{CP}$ in adults followed by the combined form. Unlike $\mathrm{CP}$ in childhood, in whom hypotonia was relatively common $(51 \%)[7,18]$, the hypotonia was reported in only $2 \%$ of adult cases and this can be explained by the fact that myelination of axons and maturation of neurons in the basal ganglia are required before spasticity and dyskinesia can be manifested. The relatively high number of dyskinesia might be explained on the basis of significant number of cases suffering from kernicterus in early neonatal period, which is an important cause of dyskinesia in patients with $\mathrm{CP}$ [9]. In children with $\mathrm{CP}$, musculoskeletal disorders occur in approximately $2.5 \%$ of patients [18], while $60 \%$ reported in adults, which is in agreement with Botts et al. and Turk et al. [11,12] observation. Musculoskeletal disorders are the leading cause of loss of independent walking or other forms

Table 3. Relation of Musculoskeletal Deformity to Development of Mental Retardation

\begin{tabular}{|c|c|c|c|}
\hline Musculoskeletal Deformities & $\begin{array}{c}\text { Mental Retardation } \\
+-\end{array}$ & Total & P Value \\
\hline \hline+ & $20(50 \%) 10(10 \%)$ & $30(60 \%)$ & 0.0001 \\
highly significant \\
\hline total & $0(52 \%) 20(40 \%)$ & $20(40 \%)$ & $50(100 \%)$ \\
\hline
\end{tabular}


of supported locomotion. Epilepsy occurs in 15-60\% of children with cerebral palsy [19], which is approximately the same that occurs in adults CP (42\%). The relatively high percentage of mental retardation $(40 \%)$ in adults might be explained by musculoskeletal deformities and speech problems, which may merely deprive the adults to use their abilities. One patient in the study suffered from severe visual impairment in one eye, which can be explained by amblyopia. Children with $\mathrm{CP}$ have strabismus of paralytic or nonparalytic form and can lead to very poor vision in one eye (amblyopia) and can interfere with certain visual skills, such as judging distance if untreated [14]. With new advances in deep brain stimulation (DBS), reconstructive surgeries and baclofen bump, many of the above mentioned complication can be minimized or even resolved.

\section{CONCLUSION}

It is concluded that even though $\mathrm{CP}$ has been predominantly considered as a childhood pathological condition, its effect continues during adult life. Adults with $\mathrm{CP}$ are at risk for many highly preventable secondary complications that causes loss of function and deterioration of quality of life. Early diagnosis, health education of patient's families and general population (to changing the concept that cerebral palsy is hopeless cases) and proper management and follow up in specialized centers are the practical solutions to tackle this old problem.

\section{CONFLICT OF INTEREST}

No financial support from any organizations or institutions was received.

\section{ACKNOWLEDGEMENTS}

I would like to thanks my colleagues in neurology department in Baghdad Teaching hospital and Rashid hospital for their kind support.

\section{REFERENCES}

[1] Davis DW. Review of cerebral palsy, part I: Description, incidence, and etiology. Neoratel Netw 1997; 16(3): 7-12.
[2] Jan B. Wallack, Charles A. Nichter. Cerebral palsy. In: Abraham M, Julien IE, Colin D, Eds. Rudoph's Pediatrics, $20^{\text {th }}$ ed. USA: Appleton \& Lange, 2000; pp. 425-76.

[3] Budawi N, Keogh JM, Dixon G, Kurinczuk JJ. Developmental out comes of newborn encephalopathy in the term infant. Indian J Pediatr 2001; 68: 527-30.

[4] Han TR, Bang MS, Lim JY, Yoon BH, Kim IW. Risk factors of cerebral palsy in preterm infants. Am J phys Med Rehabil 2002; 81: 297-303.

[5] Paneth N. Etiologic factors in cerebral palsy. Pediatr Ann 1986; 15(3): 191, 194-5, 197-201.

[6] Bottos M, Granato T, Allibrio G, Gioachin C, Pauto ML. Prevalence of cerebral palsy in north east Italy from 1965 to 1989 . Dev Med Child Neurol, 1999; 41: 26-39.

[7] Kuban KCK, Levitron AL. Cerebral palsy. N Eng J Med 1994; 330: $188-93$.

[8] Hutton JL, Cooke T, pharaoh POD. Life expectancy in children with cerebral palsy. BMJ 1994; 309: 431-35.

[9] Suzuki J, Ito M, Tomiwa K, Okuno T. A clinical study of cerebral palsy in Shiga; 1977-1986-I. Etiological analysis of various types of cerebral palsy. No To Hattatsu 1999; 31: 329-35.

[10] Humphreys P, whiting S, Pham B. Hemiparetic cerebral palsy: clinical pattern and imaging in prediction of out come. Can J Neurol Sci 2000; 27: 210-19.

[11] Bottos M, Feliciangeli A, Sciuto L, Gericke C, Vianello A. Functional status of adults with cerebral palsy and implications for treatment of children. Dev Med child Neurol 2001; 43: 516-28.

[12] Turk MA, Scandale J, Rosenbaum PF, Weber RJ. The health of women with cerebral palsy. Phy Med Rehabil Clin N Am 2001; 12: 153-68.

[13] Kwong KL, Wong SN, So KT. Epilepsy in children with cerebral palsy. Pediatr Neurol 1998; 19: 31-6.

[14] Pennefather PM, Tin W. Ocular abnormalities associated with cerebral palsy after preterm. Eye 2000; 14: 78-81.

[15] Bax M, Smyth D, Thomas A. Health care and physical handicapped young adults. BMJ 1988; 296: 1153-5.

[16] Hirst MA. Young people with disabilities what happens after 18.Child: Care, Health and Development 1983; 9: 273-84.

[17] Suzuki J, Ito M, Tomiwa K. Incidence patterns of cerebral palsy in Shiga, Japan, 1977-1986 ... an epidemiological study. No To Hattatsu 1996; 28: 60-5.

[18] Abdul-Salam A. Al-Sulaiman. Epilepsy in Saudi children with cerebral palsy. Saudi Med J 2001; 22: 19-21.

[19] Kwong KL, Wong SN, So KT. Epilepsy in children with cerebral palsy. Pediatr Neurol 1998; 19: 31-6.

Received: July 14, 2008 Revised: August 06, 2008 Accepted: December 14, 2008

(c) Mezaal et al.; Licensee Bentham Open.

This is an open access article licensed under the terms of the Creative Commons Attribution Non-Commercial License (http://creativecommons.org/licenses/by-nc/3.0/) which permits unrestricted, non-commercial use, distribution and reproduction in any medium, provided the work is properly cited. 